\title{
Lyft and Uber increase congestion in San Francisco
}

Sci. Adv. https://doi.org/10.1126/sciadv.aau2670

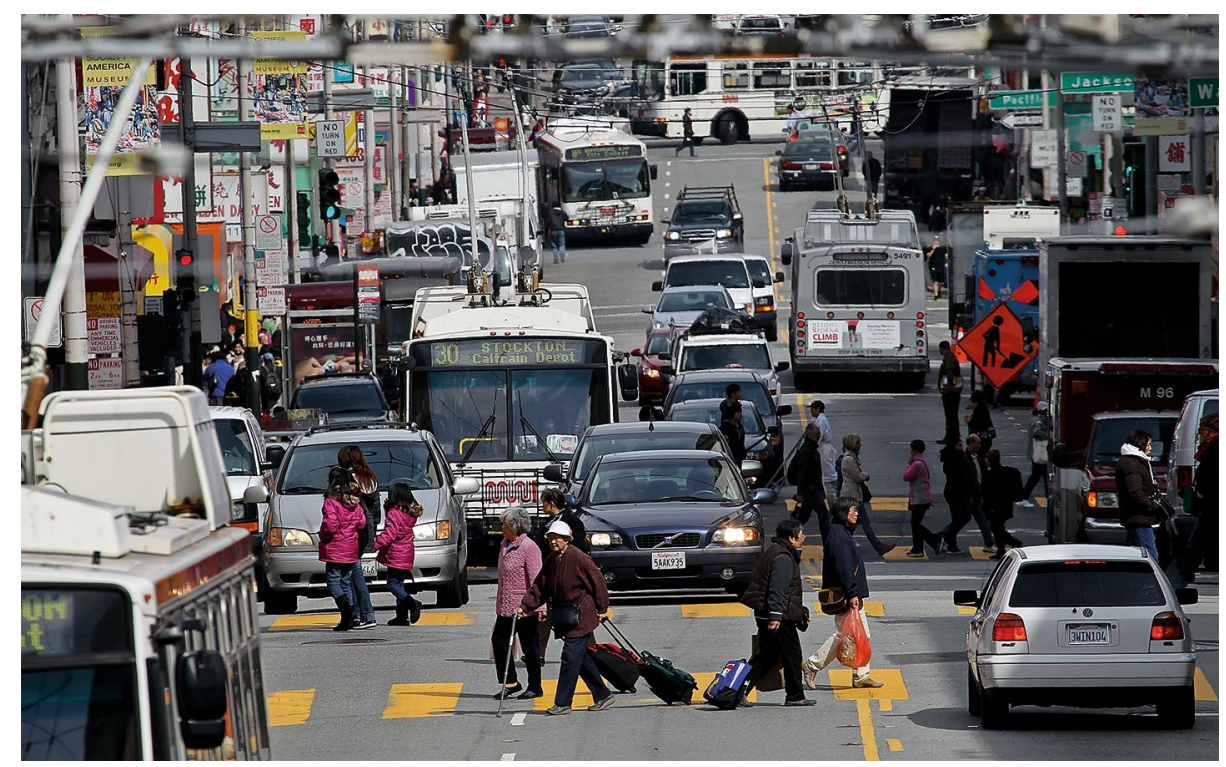

Credit: Justin Sullivan / Staff / Getty Images News / Getty

Do services such as Uber and Lyft reduce or increase traffic in cities? Previous studies have been inconclusive, generally because of a lack of comprehensive data.

Gregory Erhardt, of the University of Kentucky, and colleagues used data from the application programming interfaces of Uber and Lyft, which they analysed in the context of background traffic estimates and speed data. Comparing their analyses for 2010 (before Uber and Lyft were widely used) and 2016 (when Uber and Lyft were widely used), they find that services such as Uber and Lyft were actually the largest contributor to the growth of traffic congestion in San Francisco. In 2016, San Francisco showed an increase of $62 \%$ in traffic-related delays during the week compared to 2010. In a counterfactual scenario in which there Uber and Lyft would not exist-but the population and transportation needs remain the same-as they really were in 2016-there would have only been an increase of $22 \%$ in traffic-related delays during the week. In real-world 2016 San Francisco, delays were especially bad on roads that had more Uber and Lyft activity than on roads with less activity, regardless of the background traffic.

Taken together, these results show that Lyft and Uber have increased traffic in San Francisco. In fact, their contribution to traffic has been greater than the combined effects of population and employment growth, as well as changes in the road networks.

Mary Elizabeth Sutherland

Published online: 25 June 2019

https://doi.org/10.1038/s41562-019-0660-0 